NASA-TM-105,846

NASA Technical Memorandum 105846

\title{
Stability Testing and Analysis of a PMAD DC Test Bed for the Space Station Freedom
}

Robert M. Button

National Aeronautics and Space Administration

Lewis Research Center

Cleveland, Ohio

and

Andrew S. Brush

Sverdrup Technology, Inc.

Lewis Research Center Group

Brook Park, Ohio 


\section{STABILITY TESTING AND ANALYSIS OF A PMAD DC TEST BED FOR THE SPACE STATION FREEDOM}

\author{
Robert M. Button \\ National Aeronautics and Space Administration \\ Lewis Research Center \\ Cleveland, $\mathrm{OH} 44135$
}

\author{
Andrew S. Brush \\ Sverdrup Technology, Inc. \\ Electrical System Section \\ Brook Park, OH 44142
}

\begin{abstract}
The Power Management and Distribution (PMAD) DC Test Bed at the NASA Lewis Research Center is introduced. Its usefulness to the Space Station Freedom Electrical Power System (EPS) development and design are discussed in context of verifying system stability. Stability criteria developed by Middlebrook and Cuk are discussed as they apply to constant power DC to DC converters exhibiting negative input impedance at low frequencies. The utility-type Secondary Subsystem is presented and each component is described. The instrumentation used to measure input and output impedance under load is defined. Test results obtained from input and output impedance measurements of test bed components are presented. It is shown that the PMAD DC Test Bed Secondary Subsystem meets the Middlebrook stability criterion for certain loading conditions.
\end{abstract}

\section{INTRODUCTION}

The Space Station Freedom (SSF) Electrical Power System (EPS) is a multi-kilowatt DC power system. The eventual goal is to provide $56 \mathrm{~kW}$ ( $75 \mathrm{~kW}$ peak) of power through six (6) 9.3kW (12.5kW peak) channels. Each channel is comprised of a source subsystem, a $160 \mathrm{Vdc}$ (nominal) primary distribution system, and a $120 \mathrm{Vdc}$ secondary distribution system. The source subsystem generates and regulates the $160 \mathrm{Vdc}$ primary power. The primary distribution power is converted to $120 \mathrm{Vdc}$ by DC to DC Converters (DDCUs). The secondary distribution system then distributes the $120 \mathrm{Vdc}$ power to the SSF users.

A Power Management and Distribution (PMAD) DC Test Bed has been developed at the NASA Lewis Research Center to provide early component and systems level data to support the development of flight hardware and EPS design. The PMAD DC Test Bed consists of breadboard hardware, configured as a single EPS channel, from power sources to user loads[1].

The Space Station Freedom Electrical Power System is unique in many ways. It will be the first space-based power system that will not have clearly defined loading conditions. Over the life of the power system hundreds of loads will be attached to the power system, the majority of which are still undefined. This poses a system verification problem, the most severe being the possibility of a certain load mix causing system instability. Obviously, it is impossible to verify by test that the power system operates within specifications and is stable for all loading conditions. Therefore, it is imperative that constraints be placed in the design of the loads so that a combination of loads will not cause system instability.

Currently, a simple application of the Middlebrook stability criterion is being used as a guide by load converter designers. Although the Middlebrook criterion is normally applied to designing DC-to-DC converter input filters, the concept of instability caused by a negative impedance oscillation is also applicable at the systems level. The tests described below evaluate various input and output impedances of the PMAD DC Test Bed Secondary Subsystem to verify compliance with the Middlebrook stability criterion.

\section{MIDDLEBROOK STABILITY CRITERION}

At low frequencies, DC-to-DC converters exhibit a closed loop, negative incremental input impedance, $-R_{j}$, due to their constant power characteristics. That is, as the input voltage falls, the input current must rise to keep the input power constant. Since a DC-to-DC converter exhibits a negative impedance at low frequencies, the addition of an input filter could cause an instability. An ideal input filter has a low (positive) output impedance, $Z_{S}$, at low frequencies (Figure 1). However, the impedance rises to a resonant maximum value and the net circuit resistance (filter + converter) could become negative causing oscillations $[3, p .91]$.

Stability criteria developed by R. D. Middlebrook and S. Cuk for the design of input filters for switching-mode DCto-DC converters is discussed at great length in $[2,3]$. They describe an optimal method for designing input filters that are both stable and effect little change in the output impedance and regulation of the switch-mode converter. However, the criteria require knowledge of the internal components of the converter to meet an optimal filter design. Realizing that it is also common to design 
filters for "black box" converters in which internal components are unknown, Middlebrook investigated another widely used criterion for stability based solely on the negative input impedance, $-R_{j}$, of a switch-mode converter.

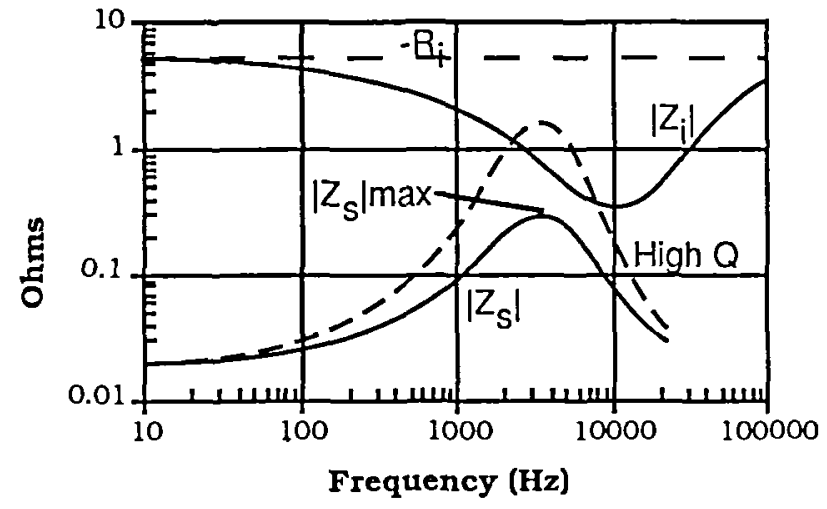

Figure 1 - Definition of Impedance Terms

As discussed in [3], a conventional rule for stability between an input filter and a DC to DC converter is:

$$
\mid Z_{\text {slmax }}<-R_{j} \text {. }
$$

where $\left|Z_{\text {s }}\right|_{\text {max }}$ is the resonant peak output impedance of the filter (Figure 1). This rule implies that the input filter be designed with low $Q$ to prevent the filter impedance from reaching a high resonant value. This could only be accomplished by increasing the ohmic resistance of the filter, thereby losing valuable efficiency points [3]. Middlebrook goes on to show that (1) will not guarantee stability and is not sufficiently general. Two cases are presented in which (1) is not satisfied yet the converter is stable, and another in which (1) is satisfied yet the converter is unstable (see High $Q$ plot in Figure 1) [3].

A more general criterion to guarantee stability is

$$
\left|Z_{s}\right|<\left|Z_{i}\right| \text {. }
$$

where $\left|Z_{i}\right|$ is the magnitude of the closed-loop input impedance of the converter for all frequencies. Middlebrook stresses that this criterion is "more-thannecessary" to ensure stability, but does not guarantee that the converter performance will be unaffected by addition of the input filter.

The results of (2) guarantee stability between an input filter with a known output impedance, and a DC to DC converter with a known closed-loop input impedance. Currently, an application of (2) is being used as a guide for designers of load converters for the Space Station EPS. In a systems context, stability at an interface of a source and a constant power converter is similar to the input filter and DC to DC converter interface discussed previously. The source has an output impedance, $Z_{s}$, and the constant power converter has a closed loop input impedance (filter included) of $\mathrm{Z}_{\mathbf{i}}$. The current specification for load converters on the Space Station state that their input impedance must be $6 \mathrm{~dB}$ above the output impedance of their secondary power interface for all frequencies. The specification is currently being evaluated to ensure that it is not overly cautious and that is does not impose unrealistic constraints on the design of load converters.

\section{SECONDARY SUBSYSTEM DESCRIPTION}

The secondary subsystem of the PMAD DC Test Bed is shown in Figure 2. Its topology is similar to a single power channel of the Space Station EPS. The subsystem converts the widely-varying primary distribution voltage to a utility-type $120 \mathrm{Vdc}$. The DC-toDC Converter Units (DDCUs) receive primary distribution voltage $(120 \mathrm{Vdc}-180 \mathrm{Vdc})$ and step it down to $120 \mathrm{Vdc}$. The DDCUs provide isolated, well regulated, utility-type power to the 23 load converters and facility loads in the test bed. Controlling the distribution of the power and providing fault protection are the Remote Power Controllers (RPCs). Finally, the secondary is populated with many different types of Load Converter Units (LCUs) all of which are DC-to-DC converters loaded by resistive loads. The hardware is described in detail below.

\section{TRW DC to DC Converter Units (DDCUs)}

The DDCUs were developed and built under an Advanced Development contract with TRW Space Systems of Redondo Beach, CA [4]. The TRW DDCUs are $6.25 \mathrm{~kW}$ converters utilizing a transformer isolated, series resonant topology. The DDCUs were originally designed as $12.5 \mathrm{~kW}$ units comprised of two $6.25 \mathrm{~kW}$ power converters in parallel with a common controller. Recent changes to the Space Station program forced the TRW DDCU to be split into two separately controlled $6.25 \mathrm{~kW}$ DDCUs with paralleling capability.

Two paralleling methads were employed in the redesigned DDCUs. The "droop" control method allows for paralleling and programmable power sharing between two DDCUs with no intra-controller connection. In droop mode, the DDCU's voltage regulator permits some voltage droop as the output power is increased. The amount of droop is controlled by setting the gain of the regulator to one of three settings. Power sharing is controlled by either changing the output voltage setpoint for each DDCU, or by setting different gains on the regulators. By changing these two values, each converter settles to a different output power level, thus contralling power sharing.

The second method employs a Master/Slave configuration. In this mode, the DDCU controllers are connected by an umbilical cable. The output voltage error bus is shared by both DDCUs. The controller developing the lowest error signal becomes the master and controls the shared error bus. The error bus signal, in each DDCU, is then analog multiplied by a fraction of 1.0. This signal is used in the current-mode control of the DDCU power stage and is proportional to the power output. By setting the multiplier through the DDCU data interface, power sharing between the two DDCUs can be controlled. 


\section{Remote Power Controllers (RPCs)}

The Remote Power Controllers (RPCs) were developed and built by Westinghouse, Electrical Systems Division of Lima, OH. They are solid state switchgear which provide on/off control, overcurrent trip, current limiting, and power telemetry functions [7]. Three types of RPC's are used in the secondary; 65A, 12A, and $3.5 \mathrm{Amp}$ RPCs.

\section{Load Converter Units (LCUs)}

Loading of the TRW DDCUs is accomplished through Load Converter Units (LCUs). These units are all DC to DC converters and represent the anticipated load converters necessary to convert the $120 \mathrm{Vdc}$ to useable voltage levels of 28,15 , and $5 \mathrm{Vdc}$. Loading is provided by programmable facility load banks. The various load converters used are described below.

\section{IRW Load Converters}

TRW Space Systems Division of Redondo Beach, CA developed three load converter topologies for use in the PMAD DC Test Bed. The three topologies: Series Resonant, Series Inductor, and Zero Voltage Switching (ZVS) all have the same specifications: output voltage (28Vdc), output power $(1 \mathrm{~kW})$, good voltage regulation, short circuit current limiting, and input over/under voltage turn-off $[6,7]$. Eight $(8)$ TRW LCUs are available for loads, six of which are ZVS units.

\section{Westinghouse Load Converters}

Westinghouse Electrical Systems Division of Lima, OH developed a $1 \mathrm{~kW}$, switching, full bridge $D C$ to $D C$ converter [6]. Specifications are the same as the TRW units: output voltage (28Vdc), output power ( $1 \mathrm{~kW})$, good voltage regulation, short circuit current limiting, and input over/under voltage turn-off. Three load converters are available as $1 \mathrm{~kW}$ constant power loads in the Secondary Subsystem.

\section{Commercial Load Converters}

Low power commercial DC to DC load converters were purchased from Vicor and Abbott [7]. These units range in power from $20 \mathrm{~W}$ to $200 \mathrm{~W}$, range in output voltage from $5 \mathrm{Vdc}$ to $48 \mathrm{Vdc}$, and are generally single switch, high frequency $(+100 \mathrm{kHz})$ converters. The Abbott and Vicor LCUs are connected to fixed resistive loads which provide full power loading.

\section{SECONDARY IMPEDANCE TESTS}

The PMAD DC Test Bed components were tested using an impedance measurement system described below. The DDCU's closed loop input impedance, $Z_{i}$, (input filter included) and output impedance, $Z_{O}$, were measured for a wide range of operating modes and conditions. Initial measurements of load converter input impedances are also taken to compare with the DDCU output impedance. Objectives of the impedance tests include the following:

1) Develop an impedance measurement system which could accurately measure the input or output impedance of any interface in the PMAD DC Test Bed.

2) Characterize the TRW DDCU input and output impedance verses power level and paralleling mode. Compare test results with current program stability requirements and Middlebrook stability criterion.

3) Provide actual test data to validate current computer models of the PMAD DC Test Bed so that further stability testing can be done using computer models.

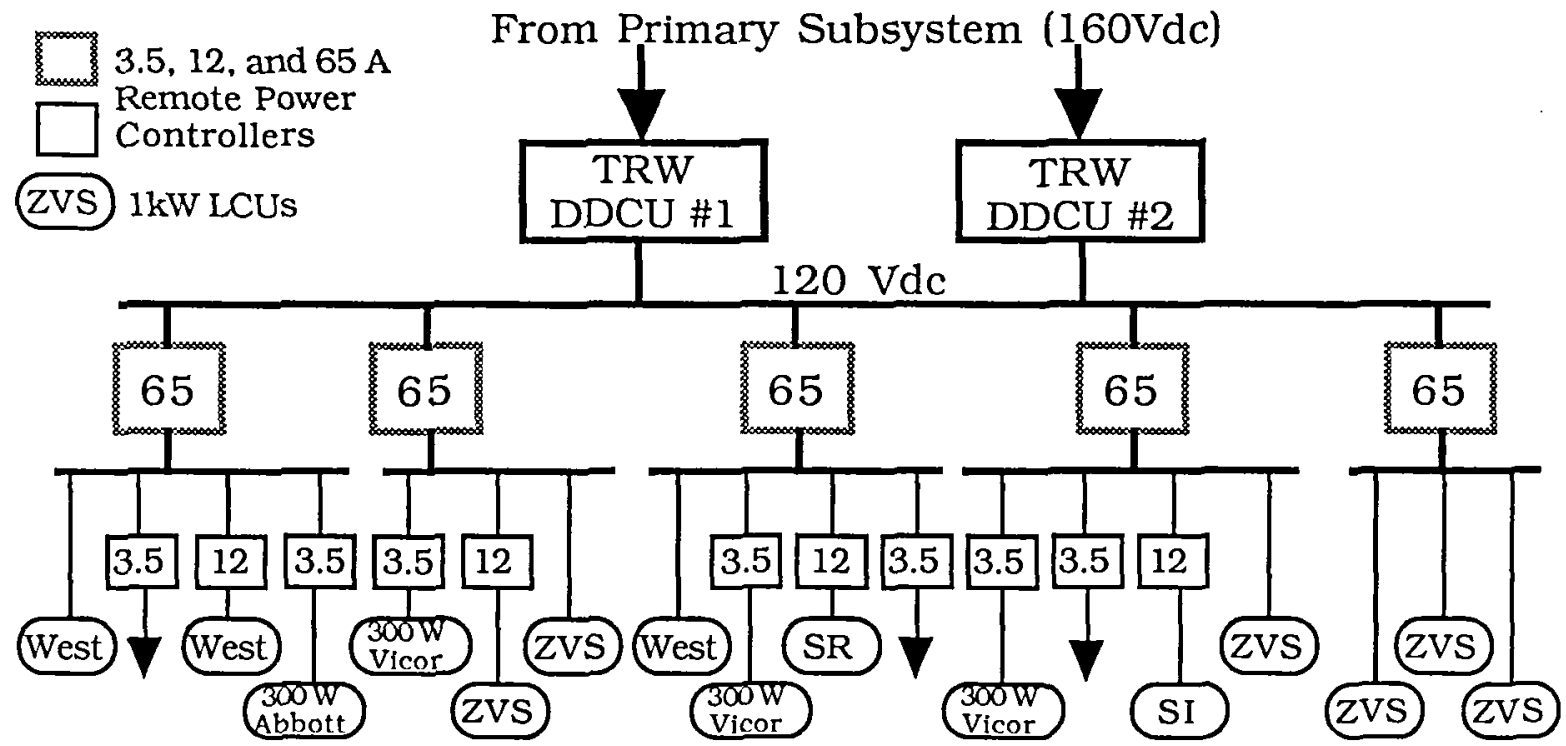

Figure 2-PMAD DC Test Bed Secondary Distribution Block Diagram 


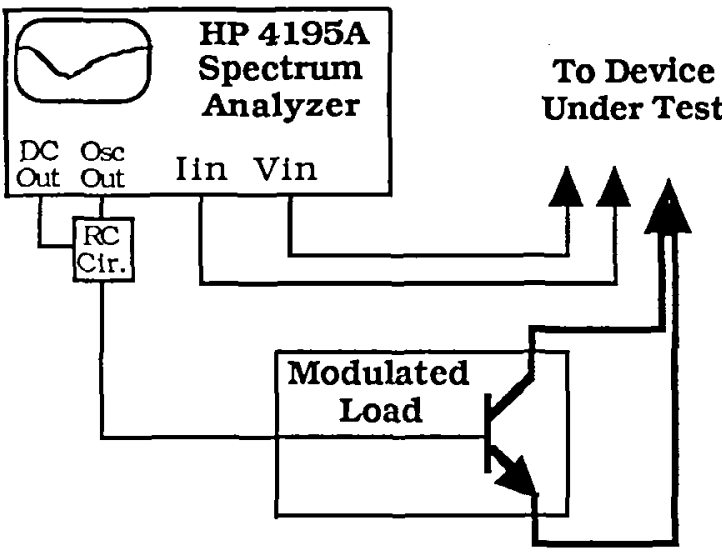

Figure 3 - Impedance Measurement System (IMS)

\section{Impedance Measurement System (IMS)}

The instrumentation used to measure the active impedance is shown in Figure 3. The system consists of: a digital spectrum analyzer with external drive signal, a programmable $6 \mathrm{~kW}$ load, and standard DC current and voltage probes. The HP 4195 Spectrum Analyzer has both a DC bias and AC oscillator output. Using an external RC circuit, the two voltages are added producing a DC voltage with an AC ripple component. This signal is used to drive a programmable load which is programmed to vary its current draw with respect to the input signal. The result is a large current ripple (5 Ap-p) at the connection of the modulated load. As the Spectrum Analyzer sweeps up the frequency range, it measures the resultant current and voltage ripple components at the specific frequency and calculates $Z(s)=V(s) /(s)$. The system is limited to impedance measurements from $10 \mathrm{~Hz}$ to $20 \mathrm{kHz}$ since the programmable load can only produce low distortion sine waves up to $20 \mathrm{kHz}$.

The placement and direction of the current probe determines whether input or output impedance is being measured (Figure 4). To measure output impedance, an output current ripple is created using the IMS and the resulting voltage ripple is measured. In this case, the

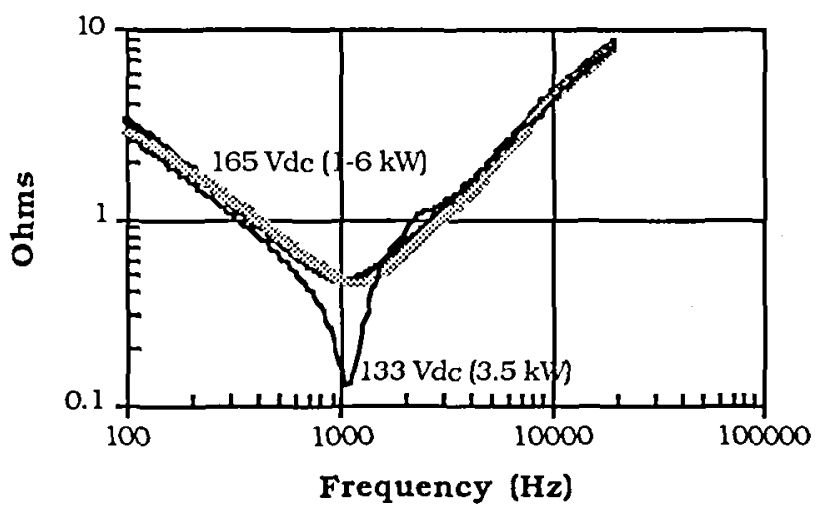

Figure 5 - TRW DDCU Input Impedance (Magnitude)

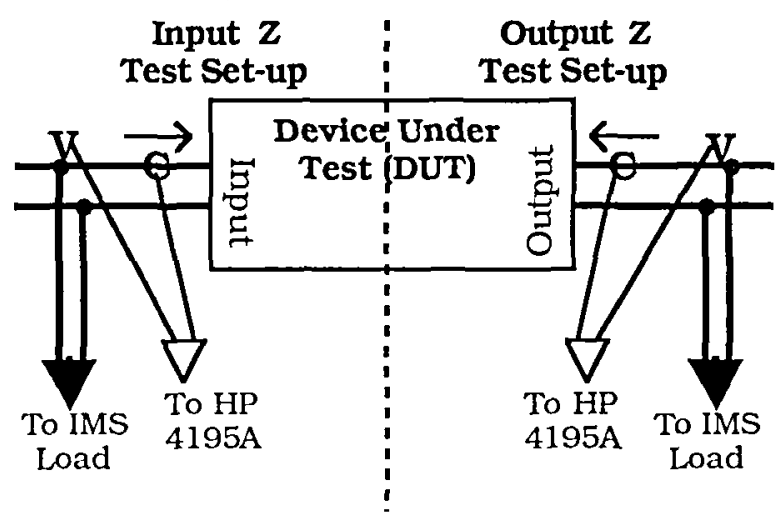

Figure 4 - Input / Output Impedance Measurement Configuration

current ripple measured is simply the current ripple created by the IMS. To measure input impedance, the IMS current ripple creates an input voltage ripple. The voltage ripple causes an input current ripple. In this case, the IMS current ripple is not measured, only the current ripple which results from the created voltage ripple.

\section{TRW DDCU Impedance Test}

Using the impedance measurement system, the input and output impedance of the TRW DDCU is measured from $100 \mathrm{~Hz}$ to $20 \mathrm{kHz}$. Results of the TRW input impedance tests are shown in Figures 5 and 6 . For this test, three power levels were tested $(1,3$, and $6 \mathrm{~kW})$ on a single DDCU operating in droop mode regulation and an input voltage of $165 \mathrm{Vdc}$. The test results shown are identical for paralleled DDCUs operating at various power levels and paralleling modes (droop and master/slave). The plot in Figure 5 shows a minimum impedance value of $0.45 \Omega$ at about $1.3 \mathrm{kHz}$. However, when the DDCU input voltage was changed from $165 \mathrm{Vdc}$ to $133 \mathrm{Vdc}$, the impedance magnitude minimum dropped to $0.13 \Omega(11 \mathrm{~dB}$ down) at about $1 \mathrm{kHz}$. Obviously, the DDCU input impedance magnitude is sensitive to variations in the input voltage. This is most likely due to the fact that incremental input impedance varies with input voltage.

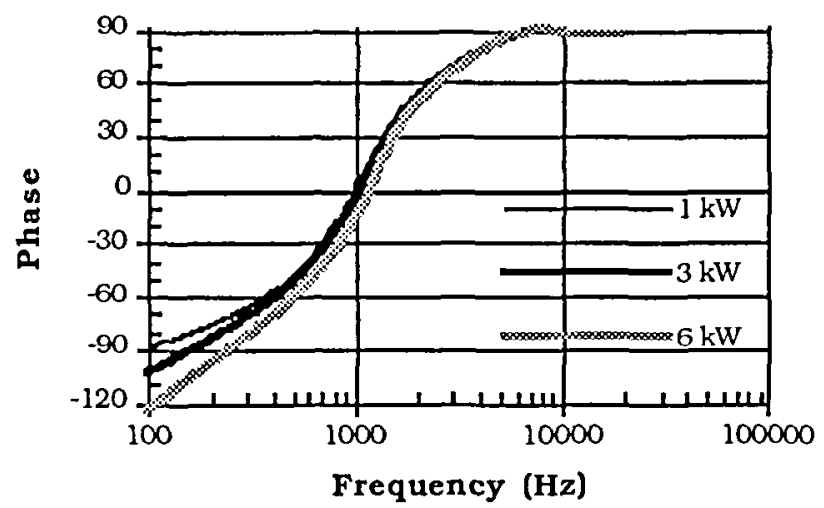

Figure 6 - TRW DDCU Input Impedance (Phase) 


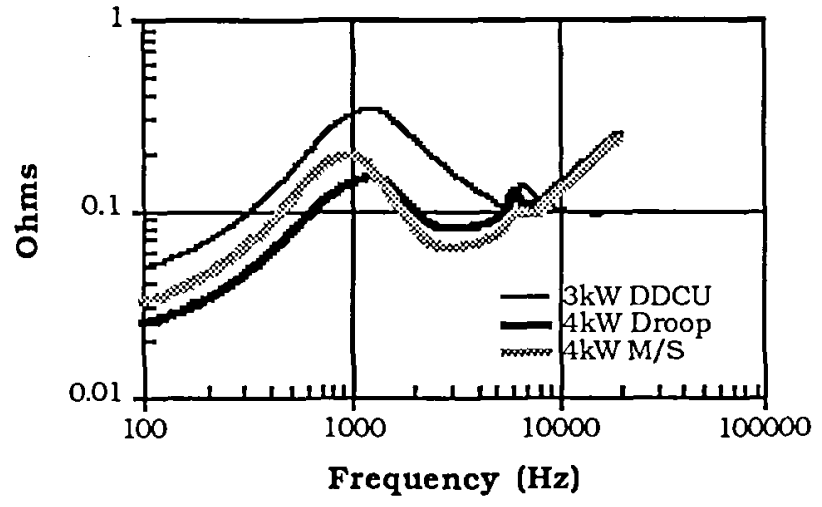

Figure 7 - DDCU Output Impedance Magnitude

Also, a lower input voltage will increase switch conduction time, thereby decreasing effective ohmic resistance and increasing effective circuit inductance. This results in a higher $Q$ filter and a lower resonant input impedance.

The input impedance of an active converter has a negative real value when the phase is $-90^{\circ}>\theta>90^{\circ}$.

$$
\operatorname{Re}[Z(s)]=|Z(s)| * \cos (\theta)
$$

The phase plot in Figure 6 displays the concept of the DC to $D C$ converter having negative impedance. The single DDCU operating at $6 \mathrm{~kW}$ has negative impedance characteristics from DC to $250 \mathrm{~Hz}$. Middlebrook states that the negative impedance characteristic vanishes well below the loop gain crossover frequency (frequency at which the control loop gain is less than unity)[3]. Tests have shown the TRW DDCU loop gain crossover to be about $1 \mathrm{kHz}$. Figure 6 also shows that the negative impedance characteristic of the DDCU varies with power level, the higher power levels having the highest negative impedance frequency band.

The output impedance of the TRW DDCU was measured for various power levels, parallel modes, and input voltages. Typical output impedance results are shown in

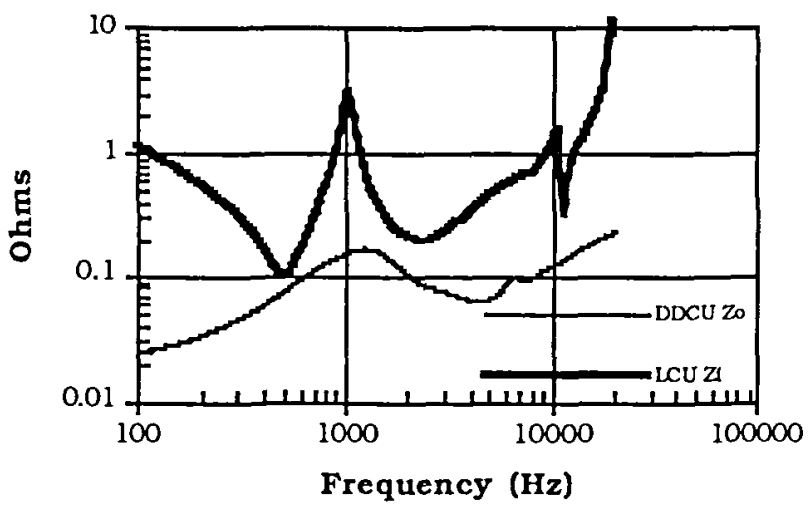

Figure 9-DDCU / Load Converter Impedance Magnitude

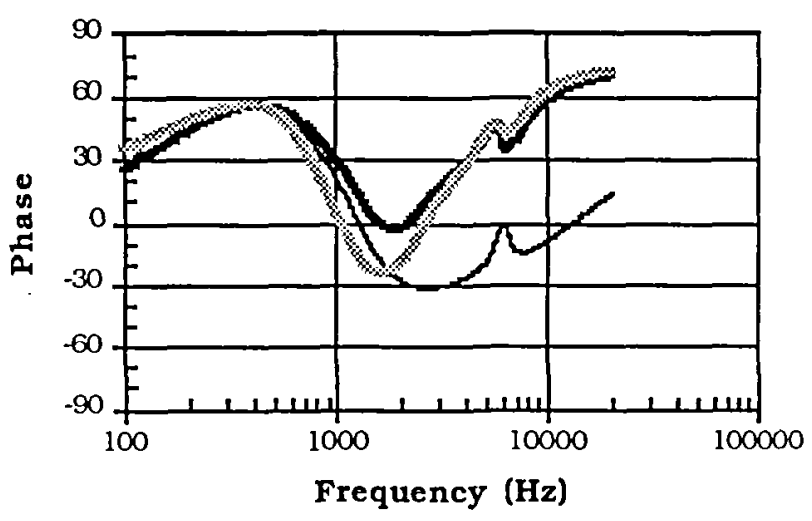

Figure 8 - DDCU Output Impedance Phase

Figures 7 and 8 . The output impedance for a single DDCU operating at $3 \mathrm{~kW}$ (in droop mode and input voltage of $165 \mathrm{Vdc}$ ) has a peak impedance of $0.4 \Omega$ at $1.3 \mathrm{kHz}$. The paralleled combination of two DDCUs lowers the output impedance peak to only $0.2 \Omega$ (3dB down) at $1 \mathrm{kHz}$ for the $4 \mathrm{~kW}$ Master/Slave mode, and $0.14 \Omega$ ( $9 \mathrm{~dB}$ down) at $1.3 \mathrm{kHz}$ for the $4 \mathrm{~kW}$ droop mode. Clearly, the output impedance of the two paralleled DDCUs is more favorable to system stability (lower $Z_{0}$ ) than the single DDCU. Also, variations in input voltage had no effect on the output impedance. The output impedance phase shown in Figure 8 shows a predominant inductive output for most frequencies.

\section{DDCU-Load Converter Interface}

Figures 9 and 10 show the results of impedance measurements taken at the DDCU interface with the load converters in the secondary subsystem. At this single interface, both a paralleled DDCU output impedance measurement and a load converter input impedance measurement was taken for a $4 \mathrm{~kW}$ load. The DDCUs were in a Master/Slave mode with an input voltage of $165 \mathrm{Vdc}$. The loads used were two TRW ZVS and one series resonant load converter $(3 \mathrm{~kW})$ plus about $700 \mathrm{~W}$ from the IMS modulated load. Results show that at this

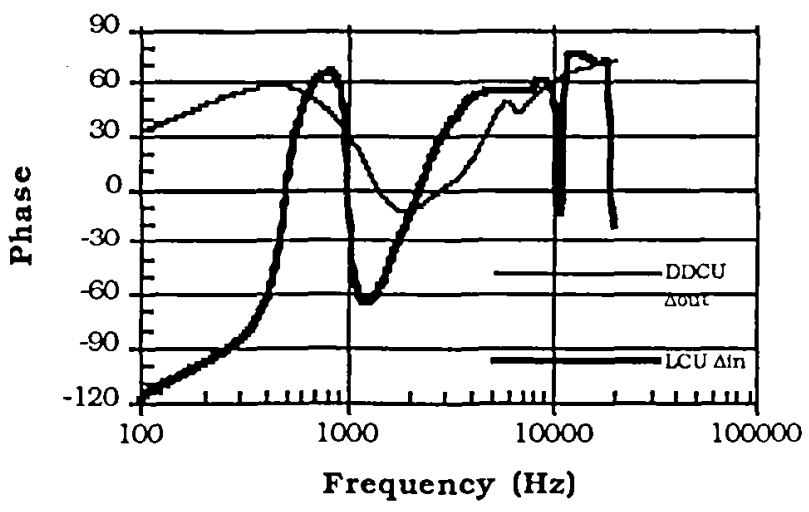

Figure 10-DDCU / Load Converter Impedance Phase 
interface, under the specific conditions outlined above, the sufficient condition for stability of (2) is met for all frequencies from $100 \mathrm{~Hz}$ to $20 \mathrm{kHz}$.

\section{Computer Modelling}

Test results of input and output impedance measurements were used to refine computer models being developed at the NASA Lewis Research Center [8]. The models being developed in EMTP are a combination of functional models of test bed components (DDCUs, LCUs) and circuit level models of cables and filters. Comparison of the computer generated impedance plots and actual test results is very good.

\section{CONCLUSIONS}

A utility-type secondary power distribution subsystem was introduced and its importance to the Space Station program was discussed. The problem of ensuring system stability for an undefined load mix was presented. Stability criteria developed by R.D. Middlebrook and S. Cuk for the design of input filters for DC to DC converters are applied to a general system interface to ensure stability.

An impedance measurement system was described which is used to measure the active input and output impedance of any DC power component. Impedance tests of paralleled TRW DC to DC converter units (DDCUs) showed that input impedance varies only with input voltage. Conversely, DDCU output impedance varies with parallel mode but not with input voltage. Comparison of the output impedance of paralleled DDCUs and the input impedance of several load converters showed that the Middlebrook stability criterion presented was met.

\section{FUTURE TESTING}

Component and systems level impedance testing will continue as new components are added and system configurations change. Using the computer models developed in EMTP, the limits of the Middlebrook stability criterion (2) will be investigated. The hope is to be able to relax the very restrictive criterion (based on (2)) currently being used in the Space Station specifications. By showing that this criterion can be relaxed, designers of load converters should be able to reduce filter weight and improve efficiency.

\section{REFERENCES}

[1] J. Soeder, R. Frye, and R. Phillips, "The Development of Testbeds to Support the Definition and Evolution of the Space Station Freedom Power System", 26th Intersociety Energy Conversion Engineering Conference, Boston, MA, August 1991.

[2] MIL-HDBK-241B, "Design Guide for Electromagnetic Interference (EMI) Reduction in Power Supplies", Appendix B, April, 1981.

[3] R.D. Middlebrook, S. Cuk, "Advances in Switched-Mode Power Conversion, Vol. 1", pg. 91-107, 1981.

[4] D. K. Decker and L. Y. Inouye, "Operation of High Power Converters In Parallel", 27th Intersociety Energy Conversion Engineering Conference, San Diego, CA, August 1992.

[5] R. Thornton and D. Fox, "Power Management and Distribution Equipment Developed for Space Applications", 26th Intersociety Energy Conversion Engineering Conference, Boston, MA, August 1991.

[6] R. Lebron, A. Oliver, and R Bodi, "Test and Evaluation of Load Converter Topologies Used in the Space Station Freedom Power Management and Distribution DC Test Bed", 26th Intersociety Energy Conversion Engineering Conference, Boston, MA, August 1991.

[7] R. Lebron, "Load Converter Interactions with the Secondary System in the Space Station Freedom Power Management and Distribution DC Test Bed", 27th Intersociety Energy Conversion Engineering Conference, San Diego, CA, August 1992.

[8] N.V. Dravid, T.J. Kacpura, and A.M. O'Connor, "EMTP Based Stability Analysis of Space Station Electrical Power System in a Test Bed Environment", 27th Intersociety Energy Conversion Engineering Conference, San Diego, CA, August 1992. 
Public reporting burden for this collection of information is estimated to average 1 hour per response, including the time for reviewing instructions, searching existing data sources, gathering and maintaining the data needed, and completing and reviewing the collection of information. Send comments regarding this burden estimate or any other aspect of this collection of information, including suggestions for reducing this burden, to Washington Headquarters Services, Directorate for information Operations and Reports, 1215 Jefferson Davis Highway, Suite 1204, Arlington, VA 22202-4302, and to the Office of Management and Budget, Paperwork Reduction Project (0704-0188), Washington, DC 20503.

\begin{tabular}{|l|l|l}
\hline 1. AGENCY USE ONLY (Leave blank) & $\begin{array}{c}\text { 2. REPORT DATE } \\
\text { August } 1992\end{array}$ & $\begin{array}{r}\text { 3. REPORT TYPE AND DATES COVERED } \\
\text { Technical Memorandum }\end{array}$ \\
\hline
\end{tabular}

\section{TITLE AND SUBTITLE}

August 1992

\section{FUNDING NUMBERS}

Stability Testing and Analysis of a PMAD DC Test Bed for the Space

Station Freedom

6. AUTHOR(S)

Robert M. Button and Andrew S. Brush

WU-474-42-10

7. PERFORMING ORGANIZATION NAME(S) AND ADDRESS(ES)

8. PERFORMING ORGANIZATION REPORT NUMBER

National Aeronautics and Space Administration

Lewis Research Center

Cleveland, Ohio 44135-3191

E-7289

9. SPONSORING/MONITORING AGENCY NAMES(S) AND ADDRESS(ES)

National Aeronautics and Space Administration

Washington, D.C. 20546-0001

10. SPONSORING/MONITORING AGENCY REPORT NUMBER

NASA TM-105846

\section{SUPPLEMENTARY NOTES}

Prepared for the 27th Intersociety Energy Conversion Engineering Conference cosponsored by the ANS, SAE, ACS, AIAA, ASME, and IEEE, San Diego, California, August 3-7, 1992. Rohert M. Button, NASA Lewis Rescarch Center, Clevcland, Ohio. Andrew S. Brush, Sverdrup Technology, Inc., NASA Lewis Rescarch Center Group, Electrical Systems Section, 2001 Aerospace Parkway, Brook Park, Ohio 44142. Responsible person, Robert M. Button, (216) 433-53.35.

12a. DISTRIBUTION/AVAILABILITY STATEMENT

12b. DISTRIBUTION CODE

Unclassified - Unlimited

Subject Category 33

13. ABSTRACT (Maximum 200 words)

The Power Management and Distribution (PMAD) DC Test Bed at the NASA Lewis Research Center is introduced. Its usefulness to the Space Station Freedom Electrical Power System (EPS) development and design are discussed in context of verifying system stability. Stability criteria developed by Middlebrook and Cuk are discussed as they apply to constant power DC to DC converters exhibiting negative input impedance at low frequencies. The utility-type Secondary Subsystem is presented and each component is described. The instrumentation used to measure input and output impedance under load is defined. Test results obtained from input and output impedance measurements of test bed components are presented. It is shown that the PMAD DC Test Bed Secondary Subsystem meets the Middlebrook stability criterion for certain loading conditions.

\section{SUBJECT TERMS}

Systems stability; Space station power supplies; Voltage converters (DC to DC)

8

16. PRICE CODE

A02

\begin{tabular}{|c|c|}
\hline $\begin{array}{l}\text { 17. SECURITY CLASSIFICATION } \\
\text { OF REPORT }\end{array}$ & $\begin{array}{l}\text { 18. SECURITY CLASSIFICATION } \\
\text { OF THIS PAGE }\end{array}$ \\
\hline Unclassified & Unclassified \\
\hline
\end{tabular}

19. SECURITY CLASSIFICATION OF ABSTRACT Unclassified

20. LIMITATION OF ABSTRACT


National Aeronautics and Space Administration

Lewis Research Center

Cleveland, Ohio 44135

Official Business

Penalty for Private Use $\mathbf{\$ 3 0 0}$

Postage and Fees Pard

National Aeronautics anc

Space Administration

NASA 451 